\title{
Analysis of chromatin binding of ectopically expressed proteins in early Xenopus embryos
}

\section{Short title:}

Chromatin binding of ectopically expressed protein

\section{Authors:}

Laura J.A. Hardwick ${ }^{1,3}$ and Anna Philpott ${ }^{1,2}$

\author{
Affiliations: \\ ${ }^{1}$ Hutchison/MRC Research Centre, Department of Oncology, University of Cambridge, \\ Cambridge, CB2 0XZ, UK. \\ ${ }^{2}$ Wellcome-MRC Cambridge Stem Cell Institute, University of Cambridge, Cambridge, UK. \\ ${ }^{3}$ Peterhouse, University of Cambridge, Cambridge, CB2 1RD, UK.
}

\section{Corresponding author:}

Professor Anna Philpott: (+44) 1223 762675; ap113@cam.ac.uk

\section{Abstract:}

Xenopus embryos have long been used to demonstrate phenotypic effects following overexpression of proteins of interest such as transcription factors, while post-translational modification of these proteins can dramatically alter the extent of the observed phenotype by inhibiting or enhancing protein activity. In order to determine the mechanisms controlling transcription factor activity, it is useful to compare relative levels of chromatin-bound protein, as this can reveal altered chromatin association in addition to changes in overall protein accumulation seen in the cytoplasm. Assaying protein binding to the bulk DNA described here compliments alternative assays such as EMSA and ChIP that measure sitespecific DNA binding. This protocol describes a method to prepare and analyse chromatin and cytoplasmic extracts from embryos over-expressing the proteins of interest, and uses a robust fractionation procedure that results in clear separation of cytoplasmic tubulin from histone-H3 enriched chromatin. This assay for relative chromatin-bound protein is most suitable for comparing modified forms of a single protein, for example to investigate the 
effects of point mutations on chromatin association. Optimisation is required for the specific protein of interest but guide ranges are provided.

\section{Materials:}

It is essential that you consult the appropriate Material Safety Data Sheets and your institution's Health and Safety Office for proper handling of equipment and hazardous material used in this protocol.

RECIPES: Please see the end of this protocol for recipes indicated by $\langle\mathrm{R}\rangle$. Additional recipes can be found online at http://cshprotocols.cshlp.org.site/recipes

\section{Reagents:}

- Antibodies for western blot - anti- $\alpha$-tubulin; anti-histone-H3; antibody for protein of interest.

As this protocol is a relative comparison of two or more over-expressed proteins, it is advisable that proteins have a common tag that can be detected with a single antibody where a protein-specific antibody is not available.

- Cross-linking solution: $1 \%$ formaldehyde in $0.1 \mathrm{x}$ modified barth's saline (MBS; CSH recipes). Prepare fresh.

- Distilled water

- $\quad$ DNase - for example (RNase free DNase; Qiagen).

- Extraction buffers: E1 <R>, E2 <R>, E3 <R>. Make solutions fresh and hold on ice.

- Fertilisation and embryo culture reagents; mRNA encoding proteins of interest, - see Protocol: Microinjection of mRNAs and Oligonucleotides (Moody 2018).

- Quenching solution $=125 \mathrm{mM}$ glycine in $0.25 \mathrm{x}$ MBS. Prepare fresh and keep at room temperature.

- Sample buffer with reducing agent for SDS-PAGE.

- Washing solution - 0.25x MBS

- Western blotting reagents - see Protocol: A rapid western blotting method for the Xenopus oocyte (Lin-Moshier and Marchant 2013).

Equipment:

- Centrifuge - benchtop, temperature controlled and chilled to $4^{\circ} \mathrm{C}$. 
- Conical tubes $-15 \mathrm{ml}$ and $50 \mathrm{ml}$ for extraction buffers.

- Dry ice <optional>

- Glass pipette with rubber suction - 1x wide bore and 1x narrow bore.

- Glass vials with screw tops $-4 \mathrm{ml}$

- Heat block at $70^{\circ} \mathrm{C}$

- Ice bucket with wet ice

- Microcentrifuge tubes $-1.5 \mathrm{ml}$

- Micro-injection equipment for Xenopus embryos - see (Moody 2018).

- Paper tissue

- Rocking platform

- Western blotting equipment - see (Lin-Moshier and Marchant 2013)

Method:

This protocol provides a visual means to assess relative chromatin association of a protein of interest, in addition to its relative protein accumulation in the cytoplasm, thus complimenting alternative EMSA and ChIP assays of DNA binding affinity. This is most suitable for comparing modified versions of a single protein, for example investigating the effects of point mutations on chromatin association, where these may have differential effects on protein stability and/or chromatin association [e.g. (Hardwick and Philpott 2015; Hardwick et al. 2016)]. Two or more proteins can be compared, limited only by the number of lanes available on SDS-PAGE. All proteins of interest should be detected with a single antibody for equivalent comparison on western blot.

Preparation of embryos

1. Microinject mRNA encoding each protein of interest into a separate dish of one or two cell-stage Xenopus embryos, keeping one dish as uninjected control embryos. See (Moody 2018).

Transcription factors are often highly unstable proteins and the amounts to be injected require individual optimisation. The highest tolerated dose should be used in the first instance with equivalent amounts for each experimental category.

Injection can be performed in a one-cell stage embryo, but for improved embryo survival, inject a half dose in each cell of a two-cell embryo. 
Inject sufficient numbers of embryos to enable cross-linking of 40 - 50 embryos (see below), although it may be possible to detect chromatin-bound protein with fewer embryos.

2. Culture embryos to the relevant stage for the protein of interest - e.g. if investigating a protein involved in primary neurogenesis, culture embryos to early neural plate stages. There is usually adequate over-expressed protein for detection in embryos from stage 10.5 onwards.

Cross linking of embryos

This part of the procedure will take approximately 2.5 hours and must be conducted when the embryos reach the appropriate stage. Once cross-linked the embryos can be snap-frozen and stored at $-80^{\circ} \mathrm{C}$ prior to subsequent fractionation. Alternatively, the embryos can be lysed directly in Buffer E1 (see below).

3. Make up cross-linking, quenching and wash solutions fresh and store at room temperature.

4. Using a wide bore glass pipette, transfer embryos in each category to respective glass vials.

5. Draw off the culture media with a narrow bore glass pipette and wash embryos three times in distilled water for five minutes per wash at room temperature on a platform rocker.

Embryos are very delicate and can easily lyse prematurely.

6. Draw off the water and fill the vial with cross-linking solution ( $1 \%$ formaldehyde in $0.1 \mathrm{x}$ MBS), securing the vial caps.

7. Incubate the vials horizontally on a platform rocker for 30 minutes, ensuring all embryos are individually spaced along the vial and not clumped together.

8. Remove the cross-linking solution and fill the vial with quenching solution (0.25x MBS with $125 \mathrm{mM}$ glycine).

9. Incubate the vials horizontally on a platform rocker for 30 minutes at room temperature. 10. Remove the quenching solution and wash twice with $0.25 \mathrm{x}$ MBS washing solution, incubating the vials horizontally on a platform rocker for 15 minutes per wash.

11. Carefully transfer an equal number of embryos (approximately 45 embryos) from each category to a clean $1.5 \mathrm{ml}$ microcentrifuge tube.

It is vital that all categories contain the same number of embryos to avoid loading errors later. 
12. Taking each vial in turn, remove as much of the wash buffer as possible and either proceed directly to chromatin extraction stages or snap freeze embryos in dry ice and store at $-80^{\circ} \mathrm{C}$.

It is vital to draw off all wash buffer as this will later lead to dilution of the cytoplasmic fraction (see below), but embryos are very delicate so care must be taken not to lyse embryos prematurely. A 10ul pipette can be used to draw liquid from around embryos.

\section{Fractionation and chromatin extraction}

This part of the procedure will take approximately 1.5 hours but can be done in isolation using frozen cross-linked embryos and prior to SDS-PAGE with storage of protein extracts at $-20^{\circ} \mathrm{C}$.

All steps should be conducted on ice and with centrifugation at $4{ }^{\circ} \mathrm{C}$.

13. Pre-chill a bench centrifuge to $4^{\circ} \mathrm{C}$ and prepare all solutions fresh on ice.

For each vial of cross-linked embryos, you will require approximately $2.5 \mathrm{ml}$ buffer E1, $2.5 \mathrm{ml}$ buffer E2 and 150ul buffer E3.

If embryos have been pre-frozen from cross-linking, thaw on ice.

14. Homogenise embryos in $50 \mu 1$ Buffer E1 by pipetting within the microcentrifuge tube. 15. Spin at $4{ }^{\circ} \mathrm{C}$ for 3 minutes at $1200 \mathrm{x} \mathrm{g}$ and collect the middle fraction (supernatant below the lipid layer and above the pigmented pellet; Figure 1A) as the cytoplasmic fraction. This can be stored on ice for immediate use or frozen at $-20^{\circ} \mathrm{C}$.

16. Use a rolled up tissue to remove the white lipid residue above the remaining pellet.

17. Resuspend the remaining pigmented pellet in $1 \mathrm{ml}$ Buffer E1.

18. Spin at $4^{\circ} \mathrm{C}$ for 2 minutes at $1200 \mathrm{x}$ g and discard the supernatant.

19. Resuspend the pellet in $1 \mathrm{ml}$ Buffer E1 and rest on ice for 10 minutes.

20. Spin at $4^{\circ} \mathrm{C}$ for 2 minutes at $1200 \mathrm{x}$ g and discard the supernatant.

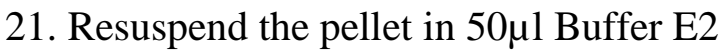

22. Spin at $4^{\circ} \mathrm{C}$ for 2 minutes at $1200 \mathrm{x}$ g and collect the supernatant as the nucleoplasmic fraction if required (Figure 1B).

23. Resuspend the pellet in $1 \mathrm{ml}$ Buffer E2.

24. Spin at $4^{\circ} \mathrm{C}$ for 2 minutes at $1200 \mathrm{x}$ g and discard the supernatant.

25. Resuspend the pellet in $1 \mathrm{ml}$ Buffer E2 and rest on ice for 10 minutes.

26. Spin at $4^{\circ} \mathrm{C}$ for 2 minutes at $1200 \mathrm{x}$ g and discard the supernatant. 
27. Resuspend the pellet in $100 \mu 1$ Buffer E3 as the chromatin fraction (Figure 1C). This can be stored on ice for immediate use or frozen at $-20^{\circ} \mathrm{C}$.

The pellet is very thick and sticky so resuspension is difficult and care must be taken not to discard material stuck to the pipette tip.

Do not resuspend in less than $100 \mu l$. There is no benefit to sample concentration as the sample becomes too viscous to run smoothly on SDS-PAGE. If proteins are difficult to detect, increase the number of embryos lysed.

Analysis of fractions by SDS-PAGE and western blotting

28. DNase treat $20 \mu 1$ of each chromatin fraction for 20 minutes at room temperature or according to DNase manufacturer's protocol.

The chromatin fractions require DNase treatment prior to SDS-reducing conditions to avoid clumping and solidification. If the protein of interest is abundant on DNA, chromatin fraction can be diluted in sterile water prior to DNase treatment.

29. Prepare equivalent samples of each cytoplasmic and DNase-treated chromatin fraction for addition of SDS-reducing buffer in a total volume of $20 \mu 1$ and heat at $70^{\circ} \mathrm{C}$ for 10 minutes on a heat block. Once cooled, check the chromatin fraction for clumping that will otherwise prevent loading on a gel. If clumping occurs, repeat DNase treatment with a reduced amount of starting material.

The amounts to load must be optimised for the individual protein of interest but will be in the region of 5-10 $\mu$ l of extract from 45 embryos, either diluted directly in sterile water for the cytoplasmic fractions or from the diluted DNase-treated chromatin sample.

30. Separate proteins by SDS-PAGE using western blotting for protein detection and determine successful fractionation by probing for $\alpha$-tubulin (wholly cytoplasmic) and histone-H3 (predominantly chromatin fraction but some present in cytoplasm).

A gradient gel (e.g. 4-20\%) can give better protein resolution across the large range of molecular sizes - e.g. 15kDa for Histone H3 and 50KDa for tubulin, plus protein of interest.

31. The density of the autoradiography band (after western blotting) corresponding to the protein of interest can be quantified relative to tubulin (cytoplasmic) or histone $\mathrm{H} 3$ (chromatin) loading controls. 
Examples to illustrate the results of this protocol are provided in (Hardwick and Philpott 2015; Hardwick et al. 2016).

Acknowledgements:

We have derived this protocol using kind advice from Matt Guille on cross-linking and from a ChIP protocol developed by Jerome Jullien.

\section{References:}

Hardwick LJ, Davies JD, Philpott A. 2016. MyoD phosphorylation on multiple C terminal sites regulates myogenic conversion activity. Biochemical and biophysical research communications 481: 97-103.

Hardwick LJ, Philpott A. 2015. Multi-site phosphorylation regulates NeuroD4 activity during primary neurogenesis: a conserved mechanism amongst proneural proteins. Neural development 10 : 15.

Lin-Moshier Y, Marchant JS. 2013. A rapid Western blotting protocol for the Xenopus oocyte. Cold Spring Harbor protocols 2013.

Moody SA. 2018. Microinjection of mRNAs and Oligonucleotides. Cold Spring Harbor protocols.

Figure legends:

Figure1: Images demonstrating the three extracts collected during fractionation.

(A) Cytoplasmic extract is collected as the middle fraction from step 15 (black arrow).

(B) Nucleoplasmic extract from step 22.

(C) Final chromatin extract from step 27.

\section{Recipes:}

Extraction buffers

Prepare each buffer fresh and store on ice during the protocol.

E1:

\begin{tabular}{|l|l|}
\hline Reagent & $\begin{array}{l}\text { Final concentration } \\
(\mathbf{1 X})\end{array}$ \\
\hline Hepes-KOH pH7.5 & $50 \mathrm{mM}$ \\
\hline $\mathrm{NaCl}$ & $140 \mathrm{mM}$ \\
\hline
\end{tabular}




\begin{tabular}{|l|l|}
\hline EDTA pH 8.0 & $1 \mathrm{mM}$ \\
\hline Glycerol & $10 \%$ \\
\hline NP-40 & $0.5 \%$ \\
\hline TritonX-100 & $0.25 \%$ \\
\hline $\begin{array}{l}\text { 1M Dithiothreitol } \\
\text { (DTT) }\end{array}$ & $1 \mathrm{mM}$ \\
\hline $\begin{array}{l}\text { Protease Inhibitor } \\
\text { Cocktail (PIC) (Roche) }\end{array}$ & $1 \mathrm{x}$ \\
\hline $\begin{array}{l}\text { Phenylmethanesulfonyl } \\
\text { fluoride (PMSF) }\end{array}$ & $0.2 \mathrm{mM}$ \\
\hline \begin{tabular}{l} 
Sterile $\mathrm{H}_{2} \mathrm{O}$ \\
\hline
\end{tabular} & \\
\hline
\end{tabular}

E2:

\begin{tabular}{|l|l|}
\hline Reagent & $\begin{array}{l}\text { Final concentration } \\
(\mathbf{1 X})\end{array}$ \\
\hline Tris pH8.0 & $10 \mathrm{mM}$ \\
\hline $\mathrm{NaCl}$ & $200 \mathrm{mM}$ \\
\hline EDTA pH8.0 & $1 \mathrm{mM}$ \\
\hline EGTA pH8.0 & $0.5 \mathrm{mM}$ \\
\hline PIC (Roche) & $1 \mathrm{x}$ \\
\hline PMSF & $0.2 \mathrm{mM}$ \\
\hline Sterile $\mathrm{H}_{2} \mathrm{O}$ & \\
\hline
\end{tabular}


E3:

\begin{tabular}{|l|l|}
\hline Reagent & $\begin{array}{l}\text { Final concentration } \\
(\mathbf{1 X})\end{array}$ \\
\hline Tris pH6.8 & $500 \mathrm{mM}$ \\
\hline $\mathrm{NaCl}$ & $500 \mathrm{mM}$ \\
\hline PIC (Roche) & $1 \mathrm{x}$ \\
\hline Sterile $\mathrm{H}_{2} \mathrm{O}$ & \\
\hline
\end{tabular}

